\title{
Hyaluronan, a double-edged sword in kidney diseases
}

\author{
Aditya Kaul ${ }^{1} \cdot$ Kavya L. Singampalli ${ }^{1,2,3} \cdot$ Umang M. Parikh ${ }^{1} \cdot{\text { Ling } \mathrm{Yu}^{1} \cdot \text { Sundeep G. Keswani }}^{1} \cdot$ Xinyi Wang $^{1}$
}

Received: 5 November 2020 / Revised: 31 March 2021 / Accepted: 30 April 2021 / Published online: 19 May 2021

(C) The Author(s) 2021

\begin{abstract}
Over the years, hyaluronic acid (HA) has emerged as an important molecule in nephrological and urological studies involving extracellular matrix (ECM) organization, inflammation, tissue regeneration, and viral sensing. During this time, many have noted the perplexing double-edged nature of the molecule, at times promoting pro-fibrotic events and at other times promoting antifibrotic events. Different molecular weights of HA can be attributed to these disparities, though most studies have yet to focus on this subtlety. With regard to the kidney, HA is induced in the initial response phase of injury and is subsequently decreased during disease progression of AKI, CKD, and diabetic nephropathy. These and other kidney diseases force patients, particularly pediatric patients, to face dialysis, surgical procedures, and ultimately, transplant. To summarize the current literature for researchers and pediatric nephrologists, this review aims to expound HA and elucidate its paradoxical effects in multiple kidney diseases using studies that emphasize HA molecular weight when available.
\end{abstract}

Keywords Acute kidney injury (AKI) · Chronic kidney disease (CKD) · Diabetic nephropathy $\cdot$ Hyaluronic acid (HA) $\cdot \operatorname{IgA}$ nephropathy $\cdot$ Kidney cancer $\cdot$ Kidney fibrosis · Obstructive uropathy $\cdot$ Vesicoureteral reflux (VUR)

\section{Introduction}

Although the origin of kidney injuries can be diverse, most lead to kidney failure, largely characterized by fibrosis [1]. Between 1995 and 2010 in the USA alone, pediatric stage 5 chronic kidney disease (CKD 5) grew in incidence from 14.6 to 15.7 cases per million population and in prevalence from 71 to 89 cases per million population. Together, these numbers present a major healthcare and psychosocial burden for young patients and their families [2]. Deciphering how kidney injuries promote fibrogenesis is critical for developing innovative therapies to prevent kidney failure.

Hyaluronan (HA), a glycosaminoglycan ubiquitously expressed by most vertebrates, has a versatile structure and function and has been increasingly implicated in the

Xinyi Wang

xinyi.wang@bcm.edu

1 Laboratory for Regenerative Tissue Repair, Division of Pediatric Surgery, Department of Surgery, Texas Children's Hospital/Baylor College of Medicine, Houston, TX 77030, USA

2 Medical Scientist Training Program, Baylor College of Medicine, Houston 77030, TX, USA

3 Department of Bioengineering, Rice University, Houston 77030, TX, USA pathogenesis of fibrosis. On one hand, HA has been shown to mediate inflammatory and pro-fibrotic reactions [3]; on the other hand, high molecular weight-HA (HMW-HA) variants can exert anti-inflammatory and anti-fibrotic effects $[4,5]$. Therefore, understanding how distinct molecular weight (MW) variants of HA transduce signals that lead to either regenerative or fibrotic responses can help combat the clinical and economic burdens of kidney disease.

The following sections will cover the current understanding of HA in kidney-related diseases while discussing its pathophysiological roles as either a mediator or cytoprotector of these diseases.

\section{Hyaluronic acid and its biological and physiological properties}

Hyaluronan (HA) is a non-sulfated glycosaminoglycan (GAG) composed of linearly repeating [glucuronate- $\beta$ 1,3$\mathrm{N}$-acetylglucosamine- $\beta$ 1,4-] residues without a core protein [6]. Each disaccharide unit of the HA chain contains one carboxyl group, giving the poly-disaccharide an overall negative charge and enabling it to act as a water reservoir within the extracellular matrix $(\mathrm{ECM})$ to provide hydration and structural and mechanical support [7]. While most research highlights the relevance of HA quantity in the context of pathological 
consequences, few have considered the importance of HA molecular mass and structure [8].

\section{Hyaluronan synthesis, degradation and inhibition}

Despite its simple core structure, the biological processes of HA synthesis and degradation are tightly controlled to mediate its structural and biological functions. HA synthases (HAS) produce HA whereas hyaluronidases (HYAL) degrade HA, both working in concert to regulate baseline HA levels and HA molecular weight. Historically, high molecular weight (HMW)-HA (> $2000 \mathrm{kDa}$ ) was thought to be exclusively synthesized by HAS1 and 2, with low molecular weight (LMW)HA being mainly produced by HAS3 [9]. However, Itano et al. reported that all three Has enzymes contribute to HMW-HA synthesis, with Has 2 specifically generating a larger HA variant above $2000 \mathrm{kDa}$ [10].

Functionally, HAS 1-3 proteins exhibit a unique expression profile during development. One group examined all three HA synthases through the stages of murine embryogenesis and showed that each synthase is differentially expressed with respect to organ, timepoint, and concentration (Table 1) [11]. As observed here, Has 1-3 are expressed at embryo (E) day 9, but the Has 2 knockout mouse displays embryonic lethality. In contrast, $\operatorname{Has} 1$ and $\operatorname{Has} 3$ knockouts and Has $1 / 3$ double knockouts do not show any such abnormality [12]. These studies suggest a pivotal role for HAS2 in embryogenesis.

HAS1 synthesizes less HA than HAS2 and HAS3 physiologically, but its activity surges upon pathological events. In support of these observations, HAS1 functions have been summarized as follows: (1) Has 1 synthesized HA attracts more leukocytes; (2) Has 1 activation is preferentially induced by inflammatory reactions; and (3) both full-length and alternatively spliced HAS1 protein isoforms have been observed in cancers [13]. Further research is needed to establish the distinct functions of the HA synthases, especially in the context of injury or disease.

Catabolic HA enzymes, specifically HYALs 1 and 2, cleave HMW-HA into LMW-HA and oligosaccharides [14,
15], with deficiency of these two HYALs leading to malfunction of organs like the kidney [16], heart [17], and lungs [18]. Conversely, HA accumulation has not been observed in Hyal3 knockout mice [15], suggesting that Hyals 1 and 2 may compensate for the loss of Hyal3. In the next section, we will discuss the paradoxical functions of HA that arise due to its MW variations and complex binding mechanisms.

\section{How molecular weight relates to HA function}

The double-edged sword approach of this review arises from the fact that HA can influence both pro- and anti-inflammatory/fibrotic reactions. Studies have reconciled this paradox by classifying HA as either pro-inflammatory/fibrotic LMW-HA or anti- inflammatory/fibrotic HMW-HA $[10,19,20]$. Per the literature, oligosaccharides are 1.7-6.1 kDa in size [21], LMW-HA is $<120 \mathrm{kDa}$ in size [22], and HMW-HA is > $900 \mathrm{kDa}$ [23].

HMW-HA (> $900 \mathrm{kDa}$ ) is the main variant observed in healthy solid tissue across species [24], and HMW-HA increases in response to body injury. We have shown that HMW-HA synthesis can be upregulated by IL-10 and it can improve regenerative repair in multiple organs $[19,22]$. HMW-HA has also been shown to improve diabetic wound healing and restore skin integrity typically lost to fibrosis in animal models [25]. In contrast, LMW-HA typically creates a pro-inflammatory state, which can initially be beneficial as it activates an immune response to remove pathogens and prevent infection after injury [26]. However, the persistence of LMW-HA in disease states leads to tissue damage and poor remodeling.

Based on research in other organs, we expect changes in HA distribution from HMW to LMW to be associated with kidney disease. Consistently, our mouse unilateral ureteral obstruction (UUO) model shows increased HMW-HA at early time points after kidney injury, which then breaks down into LMW-HA moieties, as depicted in Fig. 1 [22]. This transition is indicative of the body's natural response to injuries, where a pro-inflammatory environment is a necessary step in infection
Table 1 HAS 1-3 gene expression pattern during murine embryonic development. ("Plus" signs indicate relative concentration of each molecule.) All three Has synthases are present in the indicated organs at various timepoints throughout embryo development. Major takeaways include the highest expression of all three Has synthases in the heart at E9, with skin showing the highest expression relative to other organs from E11 to at least E17. At E17, HAS1-3 are observed in the kidney and vitreous body for the first time

\begin{tabular}{|c|c|c|c|c|c|c|c|c|c|c|c|}
\hline & \multicolumn{3}{|c|}{ E9 (embryonic stage) } & \multicolumn{2}{|l|}{ E11-13 } & \multicolumn{2}{|l|}{ E15 } & \multicolumn{4}{|l|}{ E17 } \\
\hline & Neural tube & Lung & Heart & Dermis & Mesenchyme & Epidermis & Cartilage & Epidermis & Bone & Kidney & Vitreous body \\
\hline Has 1 & ++ & ++ & +++ & +++ & ++ & ++ & ++ & ++ & & ++ & + \\
\hline Has 2 & +++ & +++ & +++ & +++ & + & + & +++ & +++ & ++ & ++ & + \\
\hline Has3 & + & + & +++ & +++ & ++ & ++ & ++ & +++ & ++ & ++ & + \\
\hline
\end{tabular}




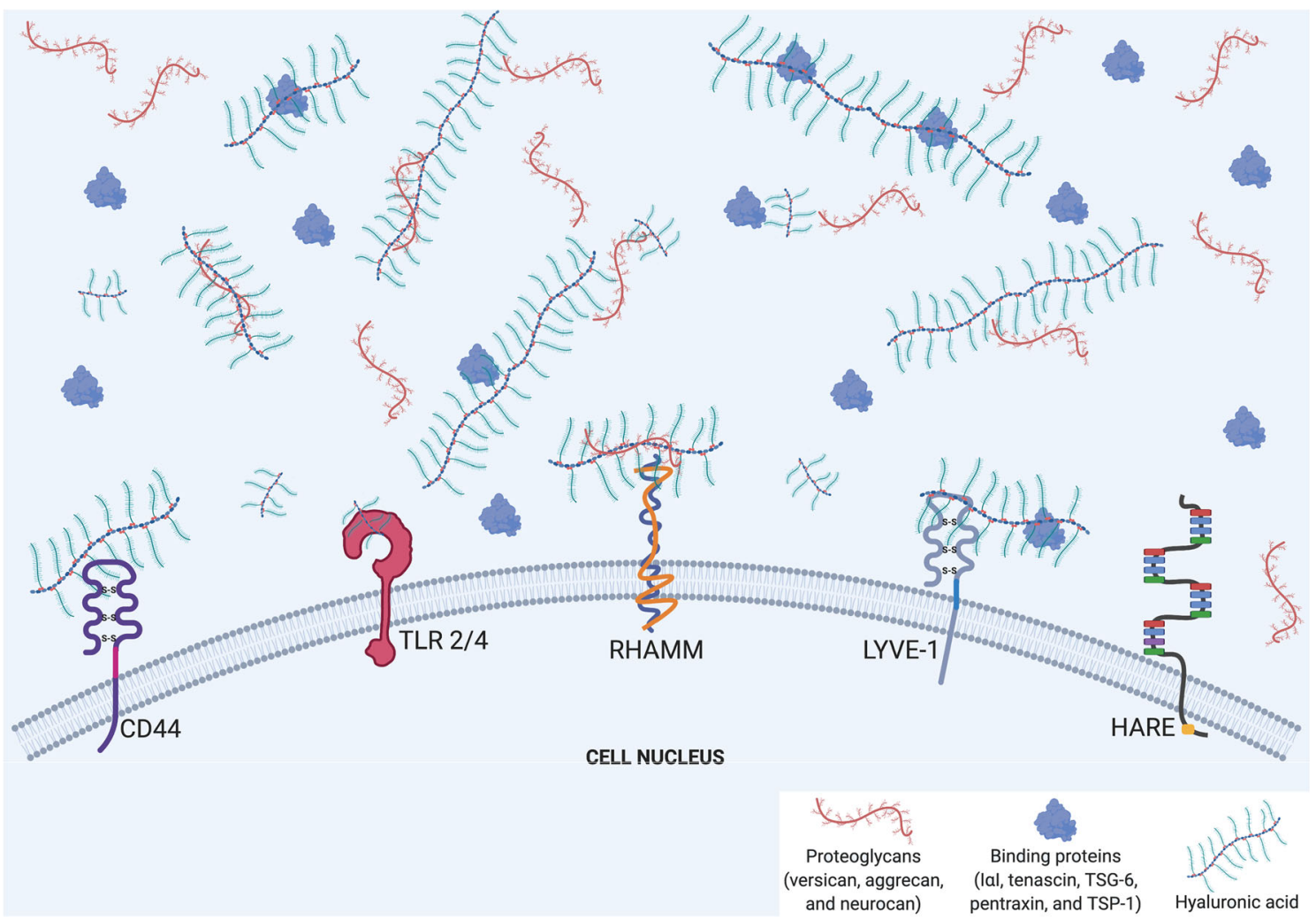

Fig. 1 Schematic illustration of the interactions of extracellular hyaluronan (HA) and its receptors and binding proteins. This figure illustrates the common binding mechanisms for extracellular HA. The major HA receptors include CD44 and its homolog, LYVE-1, in addition to TLR 2/4, RHAMM, and HARE. These receptors are present at the cell surface, with extracellular HA binding with or without binding proteins (specified in the legend). The fact that HA and its binding proteins are located outside the cell indicates that $\mathrm{HA}$ is a major component of pericellular coats. The interaction between HA and its receptors can be preferential, as LMW-HA tends to bind TLRs $2 / 4$,

and rapid healing $[27,28]$. However, in the case of chronic injury, HMW-HA is needed to promote regenerative rather than fibrotic healing [22].

\section{Hyaluronan receptors}

HA facilitates multifaceted interactions in the damaged tissues by transducing signals via specifically targeted receptors. The dichotomy between the actions of LMW-HA and HMW-HA is partially dictated by the receptors they preferentially bind. LMW-HA tends to bind TLRs 2/4 [29], which are activated by bacterial products and further induce innate immunity by signaling downstream macrophage and dendritic cells [30]. Uncontrolled inflammation with excessive macrophage and dendritic cell activation leads to slow wound closure in chronic wounds [31]. Contrarily, HMW-HA typically binds CD44 and leads to anti-inflammatory reactions to reduce macrophage infiltration and fibrosis [29]. although some, like CD44, bind both LMW- and HMW-HA. The depiction of different sizes of HA corresponds to LMW and HMW variants, which are responsible for the dichotomous pro-inflammatory/pro-fibrotic effects to anti-inflammatory/anti-fibrotic effects, respectively. In addition, crosslinks between HA and various binding proteins, including proteoglycans and other hyaladherins, modifies HA's effects. This schematic is a broad illustration and is not drawn to scale. Moreover, that five receptors are shown on one cell surface is for illustrative purposes only. Created with BioRender.com

Notably, although CD44 is a primary receptor for HMW-HA, its binding is not exclusive, so LMW-HA signaling of inflammatory pathways can periodically be transduced through the same receptor. This explains the diversity of cellular responses to injury, from inducing an anti-inflammatory environment and promoting immune cell inactivation $[32,33]$ to causing adverse tissue remodeling [34, 35]. Additionally, alternative RNA splicing and post-translational processing of the CD44 receptor molecule can produce distinct variants that alter the way HA signals and other ligands are transduced [36].

Other receptors that HA binds include the receptor for HA-Mediated Motility (RHAMM), the lymphatic endothelial cell hyaluronic acid receptor 1 (LYVE1), and the hyaluronan receptor for endocytosis (HARE). These receptors are present on various organs and multiple cell types, and HA can accordingly exert differential effects based on the receptors and their located cells. For example, HA binding LYVE1 promotes lymphatic tissue 
proliferation [37], whereas HA binding HARE in lymph nodes internalizes and clears HA [38].

\section{Hyaluronan binding proteins}

HA is known to crosslink with a variety of proteins that include inter-alpha-trypsin inhibitor ( $\mathrm{I} \alpha \mathrm{I})$, tenascin, TSG-6, pentraxin, and TSP-1 [9]. I $\alpha$ I facilitates the formation of pericellular matrix around fibroblasts and supports HMWHA stability [39], both of which are associated with scarless wound healing [19]. Proteoglycans, including biglycan, versican, aggrecan, and neurocan, represent a unique class of ECM molecules that interact with HA to guide development and response to disease [40].

As previously discussed, the effects of HA are multifold as its MW variants and auxiliary protein interactions dictate downstream signaling pathways and disease progression. The following content will focus specifically on mechanisms of HA's contribution to inflammation and fibrosis in the kidney.

\section{Hyaluronan in the kidney}

Over the past 15 years, HA has been observed to induce varying effects in kidney injury and disease that largely depend on the study model but are considerably influenced by its MW. For example, Ito et al. showed that HMW-HA bound to CD44 promotes proximal tubular cell (PTC) migration in vitro via MAPK activation [41]. Although their data support the concept that cellular responses to injury are driven by changes in
HA MW variants [42-44], the mechanisms of how HA MW influences kidney injury remain unclear [45]. We will address this gap of knowledge by exploring the multifaceted functions of HA for the pathogenesis of the most common kidney diseases in the following sections (Table 2 summarizes the effects of HMW- and LMW-HA on kidney diseases using the studies discussed in this review).

\section{Potential mechanisms of HA in kidney injury and disease}

As a primary HA receptor, CD44 has been extensively modeled in various disease studies where cognate receptorligand interactions result in increased scarring. One such study showed that increased CD44 is expressed in the injured kidneys of normal mice, and CD44 KO mice subjected to UUO showed increased tubular injury and apoptosis but decreased renal fibrosis [59]. Consistently, development of fibrotic glomerular disease has been associated with $\mathrm{CD} 44^{+}$glomerular cells [60] since cells that promote post-injury healing can be recruited, such as macrophages. Another study found that Hyal2, in conjunction with the CD44 isoform CD44v7/8, mediates bone morphogenetic protein-7 (BMP7) and regulates myofibroblast differentiation and its capacity to drive fibrosis [61].

Similarly, TLR2 mediates significant inflammatory responses after kidney injury, as evidenced by ischemia/ reperfusion (I/R) injury in a TLR2 knockout mouse model that resulted in a decrease of leukocytes, chemokines, and cytokines at the injury site. In comparison to controls, TLR2 knockout mice had decreased kidney injury. Biglycan, an HA
Table 2 The double-edged effects of HA in kidney diseases. This table outlines the beneficial and detrimental effects of HMW- and LMW-HA in the various kidney diseases discussed in this review.
Here, one can appreciate that HMW-HA lends itself to protective effects, whereas LMW-HA promotes the deleterious characteristics of each disease

\begin{tabular}{|c|c|c|}
\hline Disease & Positive effects of HA & Negative effects of HA \\
\hline $\begin{array}{l}\text { Acute kidney } \\
\text { injury (AKI) }\end{array}$ & IL-10-induced HMW-HA reduces fibrosis in I/R model [22] & $\begin{array}{l}\text { LMW-HA [46]-CD44 interaction increases the presence of } \\
\text { fibrotic molecules (collagen, } \alpha \text {-SMA) and causes tubular } \\
\text { damage [47] }\end{array}$ \\
\hline $\begin{array}{l}\text { Chronic kidney } \\
\text { diseases } \\
\text { (CKD) }\end{array}$ & $\begin{array}{l}\text { Can potentially serve as a biomarker to distinguish between CKD } \\
\text { and } \mathrm{AKI} \text { in certain clinical cases }\end{array}$ & $\begin{array}{l}\text { Increases pro-fibrotic cells and molecules (macrophage } \\
\text { presence, CD44 and LYVE-1 expression, } \alpha \text {-SMA levels) } \\
{[46]}\end{array}$ \\
\hline $\begin{array}{l}\text { Diabetic } \\
\text { nephropathy }\end{array}$ & $\begin{array}{l}\text { Maintains structure of glomerular endothelium [48]; HMW-HA } \\
\text { associated with less CD44-dependent inflammation [49] }\end{array}$ & Elevated levels associated with disease development [50] \\
\hline IgA nephropathy & & $\begin{array}{l}\text { HA-CD } 44 \text { interaction plays a role in disease development [51 } \\
\text { and fibrotic complications (crescentic glomerulonephritis) } \\
\text { [52] }\end{array}$ \\
\hline $\begin{array}{r}\text { Obstructive } \\
\text { uropathy }\end{array}$ & IL-10-induced HMW-HA reduces fibrosis [22] & $\begin{array}{l}\text { Acts as nidus for calcium stone formation to cause obstructive } \\
\text { disease [53-55] }\end{array}$ \\
\hline Transplant & Can serve as a predictive biomarker for unsuccessful transplant [56] & Associated with organ rejection [57] \\
\hline $\begin{array}{l}\text { Vesicoureteral } \\
\text { reflux }\end{array}$ & Reduces occurrence of UTIs caused by VUR [58] & \\
\hline
\end{tabular}


binding protein, can induce inflammation via TLR2/4 to recruit pro-inflammatory Th1 and Th17 subsets, ultimately leading to kidney fibrosis [62-65]. Conversely, a hyaluronidase study showed that a lack of Hyals 1 and 2 increases inflammation and alpha-smooth muscle actin (a-SMA) in an I/R injury mouse model. This underscores the roles of Hyals 1 and 2 in preventing the buildup of excessive HA to reduce inflammation and fibrosis [66].

\section{Acute kidney injury}

Acute kidney injury (AKI) continues to increase in prevalence, and with repeated injury, AKI is known to be a significant risk factor for developing chronic kidney disease (CKD) [67].

Hypoxia, an inadequate supply of oxygen to the tissue, is one leading cause of AKI. This condition, usually caused by heart and/or lung diseases, can be modeled by $I / R$ injury in preclinical animal models. Decreased HA expression has been associated with reduced inflammation and enhanced renal recovery in post-I/R injury [47]. While HA has been suggested to promote a pro-inflammatory environment in the $\mathrm{I} / \mathrm{R}$ model above, the MW variant of HA involved in the progression of the injury remains undefined. However, a similar study used the I/R injury model and found that HMW-HA accumulated one day post-injury but was found to undergo degradation into smaller fragments over time [46]. These findings suggest that LMW-HA is the likely mediator of a pro-inflammatory environment, which leads to AKI. In support of this hypothesis, we have demonstrated that the presence of IL-10-induced HMW-HA after I/R injury is cytoprotective and anti-fibrotic [22].

\section{Kidney fibrosis and CKD}

CKD is particularly impactful to children due to it being a lifelong disease with no cure. Etiology of pediatric CKD is significantly different than in adults, with congenital anomalies of the kidney and urinary tract predominating in children less than 12 years of age, and glomerulonephritis as the primary cause in older children [68].

Repetitive AKI often leads to continued activation of fibroblasts and ultimately to tubulointerstitial fibrosis, an inevitable outcome of CKD. Han et al. reported the increased expression of HA, CD44, and LYVE-1 in areas of fibrotic tissue and noted that HA accumulation was associated with an increase in $\alpha$-SMA [69], thus creating a pro-inflammatory and fibrogenic milieu in a CKD animal model.

Although the ultimate outcome of CKD is interstitial fibrosis leading to kidney failure, the identification of patients with progressive disease is challenging in the absence of high-risk biomarkers. Given the presumed role of HA as a prominent mediator of fibrosis in CKD patients, HA serum levels could help clinicians provide more assertive diagnoses. Akin et al. showed that the average HA level in sera was substantially increased in CKD patients versus AKI patients. Additionally, HA serum concentration was found to selectively correlate with serum albumin concentration and proteinuria in the CKD group [70]. These findings suggest that HA concentration in serum can serve as a biomarker to distinguish between $\mathrm{CKD}$ and $\mathrm{AKI}$ in patients with uremia and unknown kidney function.

\section{Obstructive uropathy}

Human obstructive uropathy is a common condition usually caused by kidney stones, infection, blood clots, or tumors. One study found that HA levels varied similarly between obstructed and unobstructed kidneys due to the uninjured kidney compensating for HA requirements left unfulfilled by the damaged kidney. Interstitial HA levels were noted to increase after an obstruction because papillary mesenchymal cells stimulated HA synthesis [71].

Similar to its function in AKI, HMW-HA is beneficial in reducing fibrosis after obstruction [22], indicating that HA MW could play an ameliorating role in the disease. In our recent publication, we show that HMW-HA significantly increases in the interstitium immediately after UUO onset, peaking at 3 days post-induction and indicating an initial pro-regenerative and cytoprotective response to injury. Over time, however, levels of LMW-HA increased - possibly due to uncontrolled inflammation and increased HYALs (Fig. 2)-ultimately resulting in fibrosis. A schematic illustration reveals how HMW-HA could attenuate UUO-induced interstitial fibrosis (Fig. 3).

HA is particularly relevant in obstructive uropathy because it can form gel-like matrices that are negatively charged, granting them the ability to bind crystals. Some data show HA is effective in preventing precipitation of calcium salts in solution, and under physiological conditions, HA can bind multiple calcium carboxyl groups and prevent crystallization [72]. Conversely, other reports on the role of HA in kidney stone formation have shown that it actually serves as a binder for precipitated calcium salts in the renal medulla and cortex, which can eventually lead to Randall's plaques and nephrocalcinosis [53-55]. Critically, however, none of these studies assessed the molecular weight of the HA responsible for the observed effect on obstructive pathogenesis.

\section{Diabetic nephropathy}

Diabetic nephropathy is the leading cause of CKD 5 worldwide, which can affect patients living with either type I (T1D) or type II (T2D) diabetes mellitus [73, 74]. Although T1D was traditionally associated with children and adolescents and T2D was associated with adults, rising childhood obesity 

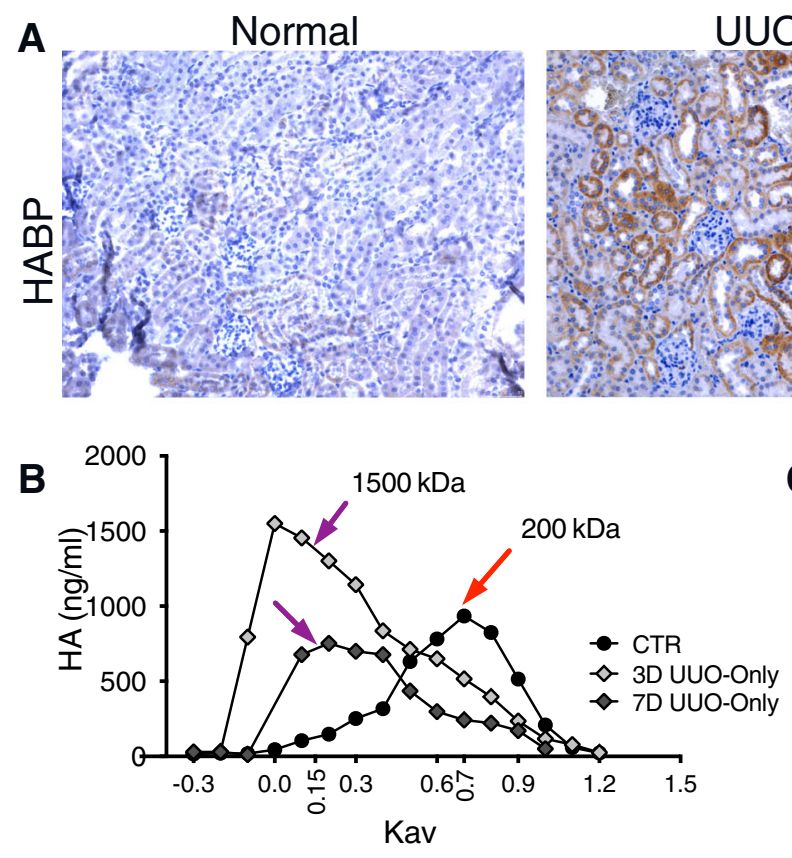

Fig. 2 HA expression and molecular weight changes in normal and diseased mouse kidneys. A. Images of HA binding protein (HABP) staining of the cortex from control, 7-day UUO kidney and 7-day IR kidney show increased HA accumulation after UUO injury. Scale bars $50 \mu \mathrm{m}$. B. Plots of total incorporated $[3 \mathrm{H}]$ in labeled HA samples were used to determine the relative MW of HA synthesized by control and 3D

has led to increased incidence of T2D in the youth population [75]. In either case, HA has long been implicated in the development of diabetic nephropathy in several in vitro studies, where elevated levels were found in diabetic animal models [50]. While HA has been identified as a mediator of interstitial fibrosis, it does not indicate the actual progression of diabetic nephropathy despite its overexpression in the kidney [73].

One of the pathologic processes leading to diabetic nephropathy is damaged endothelium, where HA is a key constituent of the glycocalyx layer and can thus serve as a more sensitive biomarker for diabetic nephropathy. To identify the effects of endothelial HA loss in diabetic nephropathy, one study found that mice lacking endothelial HAS2 exhibited an abnormal glomerular endothelial structure [48]. Similarly, another study showed decreased HA levels in diabetic rat kidneys at eight weeks [76]. HA has also been tested as a treatment for diabetic nephropathy, since HMW-HA in T2D mice reduced inflammation and glomerulosclerosis [49]. Given that diabetic nephropathy is a progressive disease, earlier detection of the disease by assessment of HA levels could have diagnostic and prognostic benefits.

\section{IgA nephropathy}

$\operatorname{Ig}$ A nephropathy (IgAN) is characterized by the accumulation of immunoglobulin A $(\operatorname{IgA})$, an antibody that
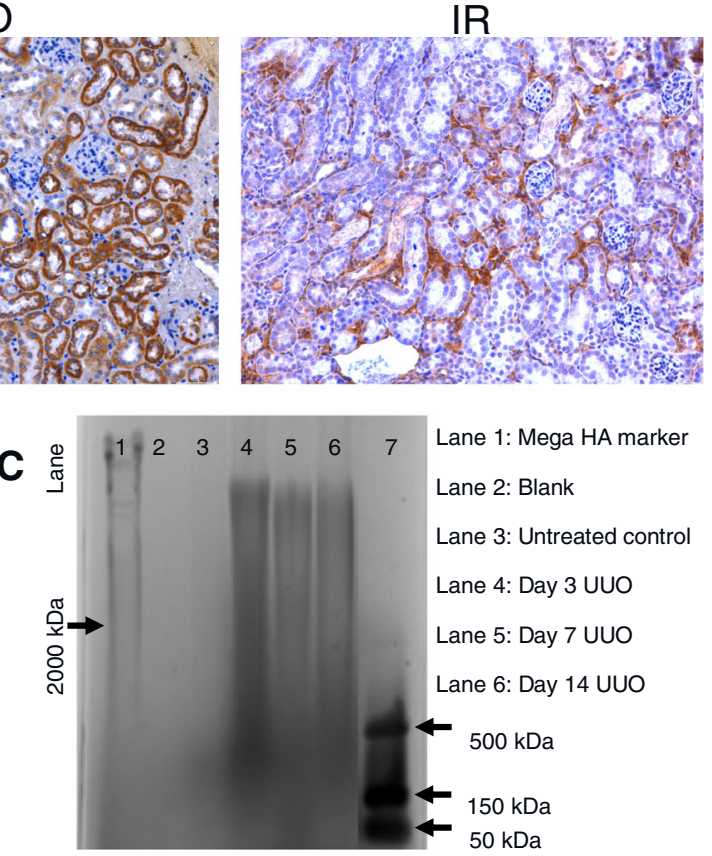

UUO kidneys ( $n \geq 3$ per condition) using Sephacryl S-1000 chromatography. Data were plotted as HA concentration versus the partition coefficient (Kav), showing an increase in HA size distribution in samples with UUO injury. C. The extracted HA from control and 3-, 7-, and 14-day untreated and treated UUO kidneys is shown on a $0.5 \%$ agarose gel electrophoresis, supporting the chromatography results

induces inflammation, in the glomeruli of the kidney. In severe cases, this inflammatory process can form irreversible fibrotic crescents that ultimately lead to CKD [77].

In conjunction with $\mathrm{HA}$, which regulates leukocyte activation and migration upon binding to CD44, osteopontin binds to the same receptor to promote cell migration and adhesion. Since HA and OPN interactions with CD44 have been implicated in crescent formation, one group investigated whether such interactions are implicated in the development of IgAN. Their work showed that not only was HA/CD44 binding associated with IgAN, but a correlation existed between the interstitial expression of osteopontin and CD44, and between the extent of tubulointerstitial damage and chronic glomerular lesions [51]. Later, another group studied the role of $\alpha$-SMA as a crescent formation-associated protein in crescentic glomerulonephritis and found that $\alpha$-SMA, CD $44, \mathrm{HA}$, and osteopontin levels are upregulated at early stages of the disease. Furthermore, CD44-HA and CD44-osteopontin complexes were found to facilitate cell-matrix and myofibroblast interactions, which likely transduce critical signals in the development of crescents [52].

These collective data suggest that interactions between $\alpha$-SMA, CD44, HA, and osteopontin play a role in the development of crescentic glomerulonephritis and that targeting HA-related actions could yield therapeutic benefits. 


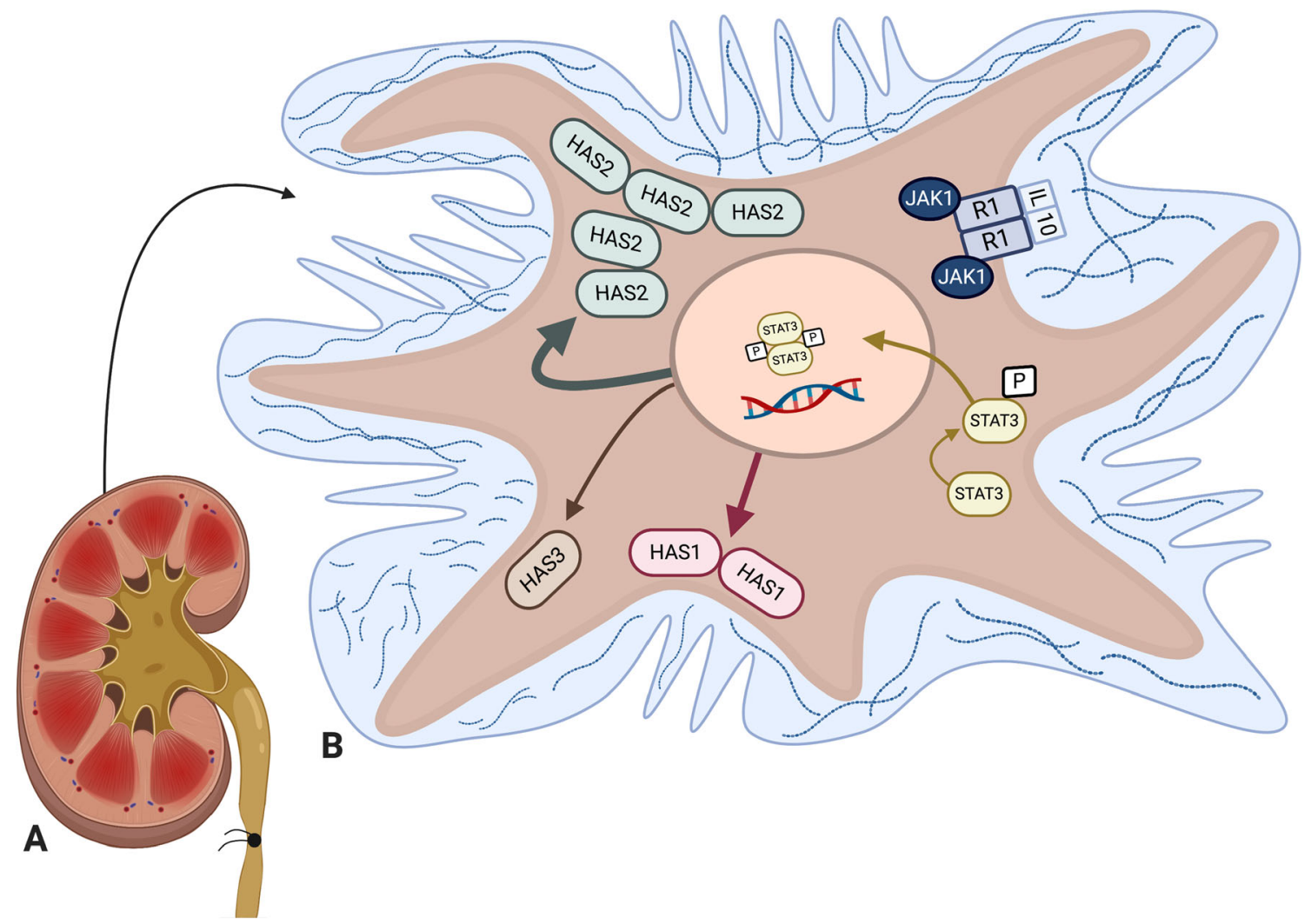

Fig. 3 IL-10 stimulation of renal fibroblasts induces HMW-HA production via STAT3 pathway. This figure is adapted from our recent publication [22]. It illustrates how IL-10 stimulates renal fibroblasts, activates the STAT3 pathway, and upregulates HA synthesis, especially HMW-HA synthesized by HAS2 which ultimately results in

\section{Vesicoureteral reflux}

Vesicoureteral reflux (VUR) is a condition occurring in $\sim 1 \%$ of the pediatric population in which urine flows retrograde from the bladder into the ureters and eventually into the kidneys [78]. VUR is classified as primary when caused by incomplete closure of valves at the vesicoureteral junction, or as secondary when caused by high pressures in the bladder [79].

HA has been tested as a therapeutic agent for this condition, with multiple clinical studies showing a Dextranomer/Hyaluronic acid (Dx/HA) injection as a safe and effective treatment for primary VUR patients. One study demonstrated that a Dx/HA copolymer decreased VUR-induced urinary tract infections (UTIs) [58], and other similar research showed a near- $85 \%$ success rate in resolution of VUR with concomitant ureteropelvic junction obstruction [80]. Since VUR also strongly correlates with kidney fibrosis, other work has shown that endoscopic treatment using Dx/HA can be effective in reducing fibrosis [81]. Furthermore, incidence rates of UTIs after open surgery are $2-5 \times$ greater than in a Dx/HA treatment, dependent on concurrent febrility [82]. The efficacy of an HA-based therapeutic in VUR highlights its cytoprotection and less fibrosis. Our data demonstrate reduced fibrosis and better-preserved tubules. A. Kidney with UUO treated with IL-10. B. Fibroblast from renal cortex with HA MW variants in ECM. This schematic is a broad illustration and is not drawn to scale. Created with BioRender.com

safety profile and sets a precedent for the potential benefits of HA in other kidney diseases.

\section{Conclusion}

Understanding the double-edged nature of HA MW variants enables insight into the seemingly paradoxical role of HA in the body. Even HMW-HA, known to be anti-inflammatory/ fibrotic, can be rendered deleterious if broken down to shorter oligosaccharides or LMW variants. These size variants and their corresponding interactions with auxiliary players like HAS, HYAL, and HA receptors and binding proteins implicate HA as part of a highly nuanced signaling pathway in various kidney diseases. In fact, the conversion of HA from HMW to LMW in context of the HAS/HA/CD44 signaling complex has been found to mediate tumor progression and thus presents a promising therapeutic target for kidney cancer research [83]. Additionally, HA can serve as a potential biomarker [56] as upregulation of HA by growth factors and cytokines has been observed in transplant rejection [57]. This results in accumulation of HA in the renal cortex and sclerotic vessels as opposed to its normal presence in the 
medulla under physiologic conditions $[84,85]$. These promising clinical use cases underscore the necessity of further research on HA and its auxiliary molecules, especially in context of its MW. As researchers uncover greater complexities of the HA signaling mechanism, these insights may be leveraged to enhance pediatric patient outcomes across various kidney diseases.

Acknowledgements The authors appreciate the editing and scientific input of Monica Fahrenholtz, Ph.D. and Hector Martinez-Valdez, Ph.D. from the Office of Surgical Research Administration. The authors would also like to acknowledge Miriam King, M.Ed. from the Office of Surgical Research for editorial assistance.

Funding This work was supported by Texas Children's Hospital Department of Surgery Clayton Award (TCPSO WANG X 2018 SURG SEED) to XW.

\section{Declarations}

Competing interests The authors declare no competing interests.

$\begin{array}{ll}\begin{array}{l}\text { Glossary } \\ \text { 4-MU }\end{array} & \begin{array}{l}\text { 4-methylumbelliferone } \\ \text { stage 5 chronic kidney disease } \\ \text { glycosaminoglycan }\end{array} \\ \text { GAG } & \text { hyaluronic acid/hyaluronan } \\ \text { HA } & \text { HA receptor for endocytosis } \\ \text { HARE } & \text { hyaluronan synthase } \\ \text { HAS } & \text { high-molecular-weight hyaluronic acid } \\ \text { HMW-HA } & \text { hyaluronidase } \\ \text { HYAL } & \text { low-molecular-weight hyaluronic acid } \\ \text { LMW-HA } & \text { lymphatic vessel endothelial HA receptor-1 } \\ \text { LYVE-1 } & \text { molecular weight } \\ \text { MW } & \text { receptor for HA-mediated motility } \\ \text { RHAMM } & \text { toll-like family receptor 2/4 } \\ \text { TLR 2/4 } & \text { unilateral ureteral obstruction } \\ \text { UUO } & \end{array}$

Open Access This article is licensed under a Creative Commons Attribution 4.0 International License, which permits use, sharing, adaptation, distribution and reproduction in any medium or format, as long as you give appropriate credit to the original author(s) and the source, provide a link to the Creative Commons licence, and indicate if changes were made. The images or other third party material in this article are included in the article's Creative Commons licence, unless indicated otherwise in a credit line to the material. If material is not included in the article's Creative Commons licence and your intended use is not permitted by statutory regulation or exceeds the permitted use, you will need to obtain permission directly from the copyright holder. To view a copy of this licence, visit http://creativecommons.org/licenses/by/4.0/.

\section{References}

1. Tecklenborg J, Clayton D, Siebert S, Coley SM (2018) The role of the immune system in kidney disease. Clin Exp Immunol 192:142150
2. (2013) Introduction to Volume One: 2012 USRDS Annual Data Report Atlas of Chronic Kidney Disease in the United States. Am J Kidney Dis 61(Suppl 1):e1-e22

3. Inokoshi Y, Tanino Y, Wang X, Sato S, Fukuhara N, Nikaido T, Fukuhara A, Saito J, Frevert CW, Munakata M (2013) Clinical significance of serum hyaluronan in chronic fibrotic interstitial pneumonia. Respirology 18:1236-1243

4. Litwiniuk M, Krejner A, Speyrer MS, Gauto AR, Grzela T (2016) Hyaluronic acid in inflammation and tissue regeneration. Wounds 28:78-88

5. Wang CT, Lin YT, Chiang BL, Lin YH, Hou SM (2006) High molecular weight hyaluronic acid down-regulates the gene expression of osteoarthritis-associated cytokines and enzymes in fibroblast-like synoviocytes from patients with early osteoarthritis. Osteoarthr Cartil 14:1237-1247

6. Nagy N, Sunkari VG, Kaber G, Hasbun S, Lam DN, Speake C, Sanda S, McLaughline TL, Wight TN, Long SR, Bollykya PL (2019) Hyaluronan levels are increased systemically in human type 2 but not type 1 diabetes independently of glycemic control. Matrix Biol 80:46-58

7. Cowman MK, Lee HG, Schwertfeger KL, McCarthy JB, Turley EA (2015) The content and size of hyaluronan in biological fluids and tissues. Front Immunol 6:261

8. Cyphert JM, Trempus CS, Garantziotis S (2015) Size matters: molecular weight specificity of hyaluronan effects in cell biology. Int J Cell Biol 2015:563818

9. Evanko SP, Tammi MI, Tammi RH, Wight TN (2007) Hyaluronandependent pericellular matrix. Adv Drug Deliv Rev 59:1351-1365

10. Itano N, Sawai T, Yoshida M, Lenas P, Yamada Y, Imagawa M, Shinomura T, Hamaguchi M, Yoshida Y, Ohnuki Y, Miyauchi S, Spicer AP, McDonald JA, Kimata K (1999) Three isoforms of mammalian hyaluronan synthases have distinct enzymatic properties. J Biol Chem 274:25085-25092

11. Törrönen K, Nikunen K, Kärnä R, Tammi M, Tammi R, Rilla K (2014) Tissue distribution and subcellular localization of hyaluronan synthase isoenzymes. Histochem Cell Biol 141:17-31

12. Camenisch TD, Spicer AP, Brehm-Gibson T, Biesterfeldt J, Augustine ML, Calabro A Jr, Kubalak S, Klewer SE, McDonald JA (2000) Disruption of hyaluronan synthase-2 abrogates normal cardiac morphogenesis and hyaluronan-mediated transformation of epithelium to mesenchyme. J Clin Invest 106:349-360

13. Siiskonen H, Oikari S, Pasonen-Seppänen S, Rilla K (2015) Hyaluronan synthase 1: a mysterious enzyme with unexpected functions. Front Immunol 6:43

14. Liang J, Jiang D, Noble PW (2016) Hyaluronan as a therapeutic target in human diseases. Adv Drug Deliv Rev 97:186-203

15. Csoka AB, Frost GI, Stern R (2001) The six hyaluronidase-like genes in the human and mouse genomes. Matrix Biol 20:499-508

16. Colombaro V, Jadot I, Declèves AE, Voisin V, Giordano L, Habsch I, Flamion B, Caron N (2015) Hyaluronidase 1 and hyaluronidase 2 are required for renal hyaluronan turnover. Acta Histochem 117: 83-91

17. Chowdhury B, Xiang B, Liu M, Hemming R, Dolinsky VW, Triggs-Raine B (2017) Hyaluronidase 2 deficiency causes increased mesenchymal cells, congenital heart defects, and heart failure. Circ Cardiovasc Genet 10:e001598

18. Chowdhury B, Hemming R, Hombach-Klonisch S, Flamion B, Triggs-Raine B (2013) Murine hyaluronidase 2 deficiency results in extracellular hyaluronan accumulation and severe cardiopulmonary dysfunction. J Biol Chem 288:520-528

19. Balaji S, Wang X, King A, Le LD, Bhattacharya SS, Moles CM, Butte MJ, de Jesus Perez VA, Liechty KW, Wight TN, Crombleholme TM, Bollyky PL, Keswani SG (2017) Interleukin10-mediated regenerative postnatal tissue repair is dependent on regulation of hyaluronan metabolism via fibroblast-specific STAT3 signaling. FASEB J 31:868-881 
20. Bollyky PL, Bogdani M, Bollyky JB, Hull RL, Wight TN (2012) The role of hyaluronan and the extracellular matrix in islet inflammation and immune regulation. Curr Diab Rep 12:471-480

21. Finke B, Stahl B, Pfenninger A, Karas M, Daniel H, Sawatzki G (1999) Analysis of high-molecular-weight oligosaccharides from human milk by liquid chromatography and MALDI-MS. Anal Chem 71:3755-3762

22. Wang X, Balaji S, Steen EH, Blum AJ, Li H, Chan CK, Manson SR, Lu TC, Rae MM, Austin PF, Wight TN, Bollyky PL, Cheng J, Keswani SG (2020) High molecular weight hyaluronan attenuates tubulointerstitial scarring in kidney injury. JCI Insight 5:e136345

23. Nagy N, Kuipers HF, Frymoyer AR, Ishak HD, Bollyky JB, Wight TN, Bollyky PL (2015) 4-methylumbelliferone treatment and hyaluronan inhibition as a therapeutic strategy in inflammation, autoimmunity, and cancer. Front Immunol 6:123

24. Armstrong SE, Bell DR (2002) Measurement of high-molecularweight hyaluronan in solid tissue using agarose gel electrophoresis. Anal Biochem 308:255-264

25. Galeano M, Polito F, Bitto A, Irrera N, Campo GM, Avenoso A, Calò M, Lo Cascio P, Minutoli L, Barone M, Squadrito F, Altavilla D (2011) Systemic administration of high-molecular weight hyaluronan stimulates wound healing in genetically diabetic mice. Biochim Biophys Acta 1812:752-759

26. Vistejnova L, Safrankova B, Nesporova K, Slavkovsky R, Hermannova M, Hosek P, Velebny V, Kubala L (2014) Low molecular weight hyaluronan mediated CD44 dependent induction of IL-6 and chemokines in human dermal fibroblasts potentiates innate immune response. Cytokine 70:97-103

27. Gariboldi S, Palazzo M, Zanobbio L, Selleri S, Sommariva M, Sfondrini L, Cavicchini S, Balsari A, Rumio C (2008) Low molecular weight hyaluronic acid increases the self-defense of skin epithelium by induction of beta-defensin 2 via TLR2 and TLR4. J Immunol 181:2103-2110

28. Gao Y, Sun Y, Yang H, Qiu P, Cong Z, Zou Y, Song L, Guo J, Anastassiades TP (2019) A low molecular weight hyaluronic acid derivative accelerates excisional wound healing by modulating proinflammation, promoting epithelialization and neovascularization, and remodeling collagen. Int J Mol Sci 20:3722

29. Liu M, Tolg C, Turley E (2019) Dissecting the dual nature of hyaluronan in the tumor microenvironment. Front Immunol 10:947

30. Avenoso A, Bruschetta G, D'Ascola A, Scuruchi M, Mandraffino G, Gullace R, Saitta A, Campo S, Campo GM (2019) Hyaluronan fragments produced during tissue injury: a signal amplifying the inflammatory response. Arch Biochem Biophys 663:228-238

31. Dasu MR, Thangappan RK, Bourgette A, DiPietro LA, Isseroff R, Jialal I (2010) TLR2 expression and signaling-dependent inflammation impair wound healing in diabetic mice. Lab Investig 90: $1628-1636$

32. Qadri M, Almadani S, Jay GD, Elsaid KA (2018) Role of CD44 in regulating TLR2 activation of human macrophages and downstream expression of proinflammatory cytokines. J Immunol 200: 758-767

33. Ruffell B, Johnson P (2008) Hyaluronan induces cell death in activated T cells through CD44. J Immunol 181:7044-7054

34. Suleiman M, Abdulrahman N, Yalcin H, Mraiche F (2018) The role of CD44, hyaluronan and NHE1 in cardiac remodeling. Life Sci 209:197-201

35. Govindaraju P, Todd L, Shetye S, Monslow J, Puré E (2019) CD44-dependent inflammation, fibrogenesis, and collagenolysis regulates extracellular matrix remodeling and tensile strength during cutaneous wound healing. Matrix Biol 75-76:314-330

36. Nagy N, Kuipers HF, Marshall PL, Wang E, Kaber G, Bollyky PL (2019) Hyaluronan in immune dysregulation and autoimmune diseases. Matrix Biol 78-79:292-313
37. Jackson DG (2019) Hyaluronan in the lymphatics: the key role of the hyaluronan receptor LYVE-1 in leucocyte trafficking. Matrix Biol 78-79:219-235

38. Garantziotis S, Savani RC (2019) Hyaluronan biology: a complex balancing act of structure, function, location and context. Matrix Biol 78-79:1-10

39. He H, Li W, Tseng DY, Zhang S, Chen SY, Day AJ, Tseng SC (2009) Biochemical characterization and function of complexes formed by hyaluronan and the heavy chains of inter-alphainhibitor (HC*HA) purified from extracts of human amniotic membrane. J Biol Chem 284:20136-42016

40. Abaskharoun M, Bellemare M, Lau E, Margolis RU (2010) Expression of hyaluronan and the hyaluronan-binding proteoglycans neurocan, aggrecan, and versican by neural stem cells and neural cells derived from embryonic stem cells. Brain Res 1327: $6-15$

41. Ito T, Williams JD, Al-Assaf S, Phillips GO, Phillips AO (2004) Hyaluronan and proximal tubular cell migration. Kidney Int 65 : 823-833

42. Zeisberg M, Neilson EG (2010) Mechanisms of tubulointerstitial fibrosis. J Am Soc Nephrol 21:1819-1834

43. Levey AS, Coresh J (2012) Chronic kidney disease. Lancet 379: $165-180$

44. Albeiroti S, Soroosh A, de la Motte CA (2015) Hyaluronan's role in fibrosis: a pathogenic factor or a passive player? Biomed Res Int 2015:790203

45. Tampe B, Steinle U, Tampe D, Carstens JL, Korsten P, Zeisberg EM, Müller GA, Kalluri R, Zeisberg M (2017) Low-dose hydralazine prevents fibrosis in a murine model of acute kidney injury-tochronic kidney disease progression. Kidney Int 91:157-176

46. Declèves AE, Caron N, Voisin V, Legrand A, Bouby N, Kultti A, Tammi MI, Flamion B (2012) Synthesis and fragmentation of hyaluronan in renal ischaemia. Nephrol Dial Transplant 27:37713781

47. Colombaro V, Declèves AE, Jadot I, Voisin V, Giordano L, Habsch I, Nonclercq D, Flamion B, Caron N (2013) Inhibition of hyaluronan is protective against renal ischaemia-reperfusion injury. Nephrol Dial Transplant 28:2484-2493

48. van den Berg BM, Wang G, Boels MGS, Avramut MC, Jansen E, Sol WMPJ, Lebrin F, van Zonneveld AJ, de Koning EJP, Vink H, Gröne HJ, Carmeliet P, van der Vlag J, Rabelink TJ (2019) Glomerular function and structural integrity depend on hyaluronan synthesis by glomerular endothelium. J Am Soc Nephrol 30:18861897

49. Campo GM, Avenoso A, Micali A, Nastasi G, Squadrito F, Altavilla D, Bitto A, Polito F, Rinaldi MG, Calatroni A, D'Ascola A, Campo S (2010) High-molecular weight hyaluronan reduced renal PKC activation in genetically diabetic mice. Biochim Biophys Acta 1802:1118-1130

50. Jones S, Jones S, Phillips AO (2001) Regulation of renal proximal tubular epithelial cell hyaluronan generation: implications for diabetic nephropathy. Kidney Int 59:1739-1749

51. Sano N, Kitazawa K, Sugisaki T (2001) Localization and roles of CD44, hyaluronic acid and osteopontin in IgA nephropathy. Nephron 89:416-421

52. Nakamura H, Kitazawa K, Honda H, Sugisaki T (2005) Roles of and correlation between alpha-smooth muscle actin, CD44, hyaluronic acid and osteopontin in crescent formation in human glomerulonephritis. Clin Nephrol 64:401-411

53. Verhulst A, Asselman M, De Naeyer S, Vervaet BA, Mengel M, Gwinner W, D'Haese PC, Verkoelen CF, De Broe ME (2005) Preconditioning of the distal tubular epithelium of the human kidney precedes nephrocalcinosis. Kidney Int 68:1643-1647

54. Asselman M, Verhulst A, De Broe ME, Verkoelen CF (2003) Calcium oxalate crystal adherence to hyaluronan-, osteopontin-, 
and CD44-expressing injured/regenerating tubular epithelial cells in rat kidneys. J Am Soc Nephrol 14:3155-3166

55. Asselman M, Verhulst A, Van Ballegooijen ES, Bangma CH, Verkoelen CF, De Broe ME (2005) Hyaluronan is apically secreted and expressed by proliferating or regenerating renal tubular cells. Kidney Int 68:71-83

56. Rostved AA, Ostrowski SR, Peters L, Lundgren JD, Hillingsø J, Johansson PI, Rasmussen A (2018) Hyaluronic acid is a biomarker for allograft dysfunction and predicts 1-year graft loss after liver transplantation. Transplant Proc 50:3635-3643

57. Wells A, Larsson E, Hanás E, Laurent T, Hällgren R, Tufveson G (1993) Increased hyaluronan in acutely rejecting human kidney grafts. Transplantation 55:1346-1349

58. Pichler R, Buttazzoni A, Rehder P, Bartsch G, Steiner H, Oswald J (2011) Endoscopic application of dextranomer/hyaluronic acid copolymer in the treatment of vesico-ureteric reflux after renal transplantation. BJU Int 107:1967-1972

59. Rouschop KM, Sewnath ME, Claessen N, Roelofs JJ, Hoedemaeker I, van der Neut R, Aten J, Pals ST, Weening JJ, Florquin S (2004) CD44 deficiency increases tubular damage but reduces renal fibrosis in obstructive nephropathy. J Am Soc Nephrol 15:674-686

60. Eymael J, Sharma S, Loeven MA, Wetzels JF, Mooren F, Florquin S, Deegens JK, Willemsen BK, Sharma V, van Kuppevelt TH, Bakker MA, Ostendorf T, Moeller MJ, Dijkman HB, Smeets B, van der Vlag J (2018) CD44 is required for the pathogenesis of experimental crescentic glomerulonephritis and collapsing focal segmental glomerulosclerosis. Kidney Int 93:626-642

61. Midgley AC, Duggal L, Jenkins R, Hascall V, Steadman R, Phillips AO, Meran S (2015) Hyaluronan regulates bone morphogenetic protein-7-dependent prevention and reversal of myofibroblast phenotype. J Biol Chem 290:11218-11234

62. Leemans JC, Stokman G, Claessen N, Rouschop KM, Teske GJ, Kirschning CJ, Akira S, van der Poll T, Weening JJ, Florquin S (2005) Renal-associated TLR2 mediates ischemia/reperfusion injury in the kidney. J Clin Invest 115:2894-2903

63. Nastase MV, Zeng-Brouwers J, Beckmann J, Tredup C, Christen U, Radeke HH, Wygrecka M, Schaefer L (2018) Biglycan, a novel trigger of Th1 and Th17 cell recruitment into the kidney. Matrix Biol 68-69:293-317

64. Göransson V, Johnsson C, Jacobson A, Heldin P, Hällgren R, Hansell P (2004) Renal hyaluronan accumulation and hyaluronan synthase expression after ischaemia-reperfusion injury in the rat. Nephrol Dial Transplant 19:823-830

65. Michael DR, Phillips AO, Krupa A, Martin J, Redman JE, Altaher A, Neville RD, Webber J, Kim MY, Bowen T (2011) The human hyaluronan synthase 2 (HAS2) gene and its natural antisense RNA exhibit coordinated expression in the renal proximal tubular epithelial cell. J Biol Chem 286:19523-19532

66. Colombaro V, Jadot I, Declèves AE, Voisin V, Giordano L, Habsch I, Malaisse J, Flamion B, Caron N (2015) Lack of hyaluronidases exacerbates renal post-ischemic injury, inflammation, and fibrosis. Kidney Int 88:61-71

67. Hsu RK, Hsu CY (2016) The role of acute kidney injury in chronic kidney disease. Semin Nephrol 36:283-292

68. Harambat J, van Stralen KJ, Kim JJ, Tizard EJ (2012) Epidemiology of chronic kidney disease in children. Pediatr Nephrol 27:363-373

69. Han DH, Song HK, Lee SY, Song JH, Piao SG, Yoon HE, Ghee JY, Yoon HJ, Kim J, Yang CW (20100 Upregulation of hyaluronan and its binding receptors in an experimental model of chronic cyclosporine nephropathy. Nephrology (Carlton) 15:216-224

70. Akin D, Ozmen S, Yilmaz ME (2017) Hyaluronic acid as a new biomarker to differentiate acute kidney injury from chronic kidney disease. Iran J Kidney Dis 11:409-413

71. Johnsson C, Hällgren R, Wahlberg J, Tufveson G (1997) Renal accumulation and distribution of hyaluronan after ureteral obstruction. Scand J Urol Nephrol 31:327-331

72. Lamontagne CA, Plante GE, Grandbois M (2011) Characterization of hyaluronic acid interaction with calcium oxalate crystals: implication of crystals faces, $\mathrm{pH}$ and citrate. J Mol Recognit 24:733-740

73. Lewis A, Steadman R, Manley P, Craig K, de la Motte C, Hascall V, Phillips AO (2008) Diabetic nephropathy, inflammation, hyaluronan and interstitial fibrosis. Histol Histopathol 23:731-739

74. Stridh S, Palm F, Hansell P (2012) Renal interstitial hyaluronan: functional aspects during normal and pathological conditions. Am J Phys Regul Integr Comp Phys 302:R1235-R1249

75. Pettitt DJ, Talton J, Dabelea D, Divers J, Imperatore G, Lawrence JM, Liese AD, Linder B, Mayer-Davis EJ, Pihoker C, Saydah SH, Standiford DA, Hamman RF, SEARCH for Diabetes in Youth Study Group (2014) Prevalence of diabetes in U.S. youth in 2009: the SEARCH for diabetes in youth study. Diabetes Care 37:402408

76. Pourghasem M, Nasiri E, Sum S, Shafi H (2013) The assessment of early glycosaminoglycan concentration changes in the kidney of diabetic rats by critical electrolyte concentration staining. Int $\mathbf{J}$ Mol Cell Med 2:58-63

77. Rodrigues JC, Haas M, Reich HN (2017) IgA nephropathy. Clin J Am Soc Nephrol 12:677-686

78. Mak RH, Kuo HJ (2003) Primary ureteral reflux: emerging insights from molecular and genetic studies. Curr Opin Pediatr 15:181-185

79. Bundy DG (2007) Vesicoureteral reflux. Pediatr Rev 28:e6-e8 discussion e8

80. Kajbafzadeh AM, Tourchi A, Ebadi M (2013) The outcome of initial endoscopic treatment in the management of concomitant vesicoureteral reflux and ureteropelvic junction obstruction. Urology 81:1040-1045

81. Blais AS, Morin F, Cloutier J, Moore K, Bolduc S (2015) Efficacy of dextranomer hyaluronic acid and polyacrylamide hydrogel in endoscopic treatment of vesicoureteral reflux: a comparative study. Can Urol Assoc J 9:202-206

82. Elmore JM, Kirsch AJ, Heiss EA, Gilchrist A, Scherz HC (2008) Incidence of urinary tract infections in children after successful ureteral reimplantation versus endoscopic dextranomer/hyaluronic acid implantation. J Urol 179:2364-2367 discussion 2367-2368

83. Karousou E, Misra S, Ghatak S, Dobra K, Götte M, Vigetti D, Passi A, Karamanos NK, Skandalis SS (2017) Roles and targeting of the HAS/hyaluronan/CD44 molecular system in cancer. Matrix Biol 59:3-22

84. Wells AF, Larsson E, Tengblad A, Fellström B, Tufveson G, Klareskog L, Laurent TC (1990) The localization of hyaluronan in normal and rejected human kidneys. Transplantation 50:240 243

85. Hansell P, Göransson V, Odlind C, Gerdin B, Hällgren R (2000) Hyaluronan content in the kidney in different states of body hydration. Kidney Int 58:2061-2068

Publisher's note Springer Nature remains neutral with regard to jurisdictional claims in published maps and institutional affiliations. 